\title{
MRI AND 'H-MRS FINDINGS OF THREE PATIENTS WITH SJÖGREN-LARSSON SYNDROME
}

\author{
Mauro Nakayama', Daniel G.F. Távora², Thereza C.L. Alvim³, \\ Alexandre C.B. Araújo4, Rômulo L. Gama ${ }^{5}$
}

\begin{abstract}
Sjögren-Larsson syndrome (SLS) is a rare autosomal recessive neurocutaneous disorder caused by deficiency of the microsomal enzyme fatty aldehyde dehydrogenase. Patients present the classical triad of congenital ichthyosis, mental retardation and spastic di- or tetraplegia. Magnetic resonance imaging (MRI) of the brain usually shows hypomyelination involving the periventricular white matter. Cerebral p roton MR spectroscopy ('H-MRS) reveals a characteristic abnormal lipid peak. We report three cases of SLS from different families with the typical clinical triad. The MRI and ${ }^{1} \mathrm{H}-\mathrm{MRS}$ findings are discussed.
\end{abstract}

KEY WORDS: Sjögren-Larsson syndrome, magnetic resonance imaging, proton spectroscopy.

\section{Sín d rome de Sjögren-Larsson: achados à ressonância magnética e espectroscopia de prótons em três pacientes}

\begin{abstract}
RESUMO - A síndrome de Sjögren-Larsson (SJL) é distúrbio raro, autossômico recessivo, caracterizado pela tríade clássica de ictiose congênita, reta rob mental e tetraplegia ou diplegia espástica. Trata-se de um erro inato do metabolismo dos lipídios, causado pela deficiência da enzima microssômica aldeído graxo desidrogenase. Os achados de imagem do encéfalo na SJL demonstram atrofia cerebral e alteração da substância branca. A espectroscopia de prótons, com poucos casos relatados, caracteriza-se pelo elevado pico de lipídios e redução de $\mathrm{N}$-acetil-aspartato. Apresentamos três casos de SJL, com ênfase nos achados da ressonância magnética e da espectroscopia de prótons.
\end{abstract}

PALAVRAS-CHAVE: síndrome de Sjögen-Larsson, ressonância magnética, espectroscopia de prótons.

Sjö g ren-Larsson syndrome (SLS) is a rare autosomal recessive neurocutaneous disorder characterized by the clinical triad of congenital ichthyosis, mental re ta rotation and spastic diplegia or tetraplegia. Additional findings include retinal pigmentary degeneration in the macular region, epilepsy, hypoplasia of teeth, kyphosis and metaphyseal dysplasia ${ }^{1,2}$. SLS is an inborn error of lipid metabolism caused by a deficiency of the microsomal enzyme fatty aldehyde dehyd rogenase (FALDH), a component of the fatty alcohol: NAD+ oxid oreductase enzyme complex. FALDH deficiency may lead to an accumulation of long-chain fatty alcohols with structural consequences for cellmembrane integrity, which disrupt the barrier function of the skin and the white matter of the brain ${ }^{3}$.

Reports on central nervous system imaging of SLS have described brain atrophy and white matter disease characterized by hypomyelination ${ }^{4-6}$. However, there are only a few reports on brain proton magnetic resonance spectroscopy ('H-MRS), with typical find- ings of abnormal high peak in spectral curve, between 0.8 and $1.6 \mathrm{ppm}$, corresponding to the range of lipids. It is also re $p$ o rted a nonspecific diminished peak of N-Acetyl Aspartate (NAA) at the periventricular white matter ${ }^{1,2,7}$.

We present three cases of SLS from different families with the typical clinical triad. The magnetic resonance imaging (MRI) and ${ }^{1} \mathrm{H}-\mathrm{MRS}$ findings are discussed.

\section{CASES}

Case 1 - A 16-year-old girl presented with ichthyosis and spastic diplegia. She was the first child of consanguineous Brazilian parents. She was born after an uneventful full term pregnancy, and developmental delay was noticed at very early infancy, sitting at 2 years of age and crawling at 4 years. Generalized ichthyosis and pruritus were additional features, with gradual worsening (Fig 1A). She had no past history of epilepsy.

On examination, her height was $140 \mathrm{~cm}\left(<5^{\text {th }}\right.$ percentile), and her weight was $39.3 \mathrm{~kg}\left(<5^{\text {th }}\right.$ pe rentile). Neurological

Sarah Network of Rehabilitation Hospitals - Fortaleza CE, Brazil: 1,2,3,5Radiologist; ${ }^{4}$ Pediatrician.

Received 6 October 2005, received in final form 8 December 2005. Accepted 7 February 2006.

Dr. Mauro Nakayama - Av. Juscelino Kubitschek 4500 - 60861-630 Fortaleza CE - Brasil. E-mail: mauronakayama@sarah.br 


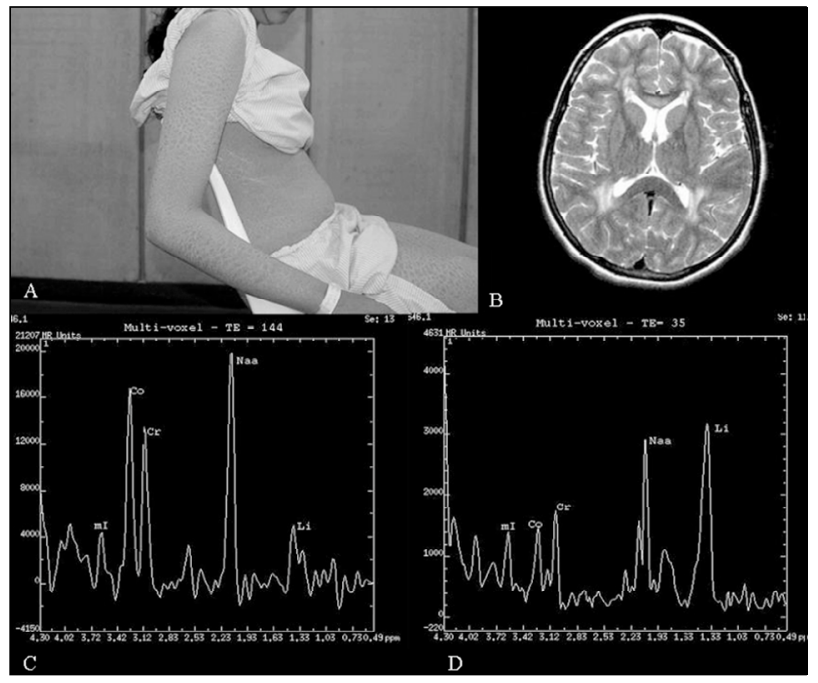

Fig 1. Patient 1. (A) Photographs of the skin abnormalities of the trunk and limbs (ichthyosis). (B) Axial T2-weighted FSE (Fast Spin Echo) images show prominent hyperintensity in the periventricular white matter. (C) and (D) Multivoxel ${ }^{1} \mathrm{H}-M R S$. Peritrigonal spectral analysis shows a high lipid peak at $T E=144$ $\mathrm{ms}(C)$ and a less prominent lipid peak at $T E=35 \mathrm{~ms}(D)$.

examination disclosed mental retardation, spasticity in both lower limbs, increased patellar reflexes and ankle clonus. Babinski's sign was positive bilaterally. EEG and nerve conduction studies were normal. Multislice computed tomography (CT) scan of the brain showed diffuse periventricular white matter low density and a mild cerebral atrophy (not shown).

$\mathrm{MRI}$ at 1.5 T demonstrated diffuse and symmetric high signal areas in the periventricular white matter on T2weighted images, most prominent around the trigones (Fig 1B). The area of abnormally high signal intensity on T2weighted images had a decreased signal intensity on T1weighted images. ${ }^{1} \mathrm{H}-\mathrm{MRS}$ (single and multivoxel, TE=35 ms and $144 \mathrm{~ms}$ ) was performed with the voxel located at the peritrigonal area and showed a high lipid peak and a slightly low NAA peak (Figs 1C and 1D).

Case 2 - A 11-year-old boy presented with cutaneous symptoms since birth, delayed milestones and speech development. He was the only child of consanguineous Brazilian parents, born at about 32 weeks of gestational age through a cesarean delivery. He was examined by a neurologist during early infancy and a diagnosis of cerebral palsy was made. The ichthyosis was confirmed by skin biopsy. The parents noted a cognitive developmental delay and difficult walking. He also had dysarthria.

On examination, his height was $143 \mathrm{~cm}$ (percentile 50) and his weight was $36 \mathrm{~kg}$ (percentile 50). Neurological examination revealed spastic diplegia, increased deep tendon reflexes, positive Babinski's sign and ankle clonus. He was able to walk a short distance with aids, and had no diff iculties in crawling. Conduction nerve studies were normal.

Brain MRI showed bilateral and symmetric slightly ab-

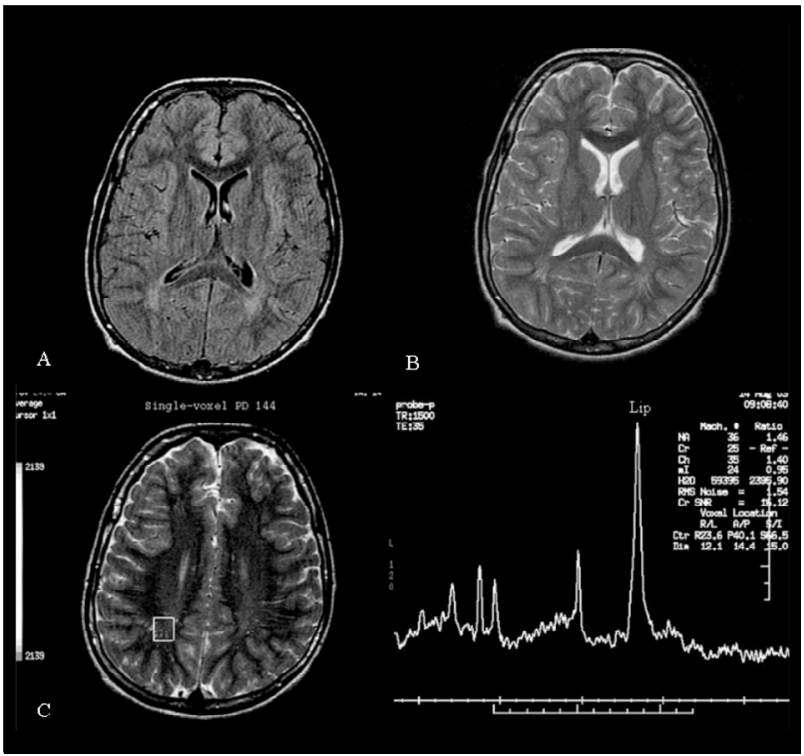

Fig 2. Patient 2. (A) Axial FLAIR (Fluid Attenuated Inversion Recovery) images and (B) axial T2-weighted FSE (Fast Spin Echo) images shows minimal hyperintensity in the peritrigonal white matter. (C) Single voxe ${ }^{1} \mathrm{H}-\mathrm{MRS}$ (TE=35 ms) shows a sharp and abnormally high peak at the spectral range of lipids.

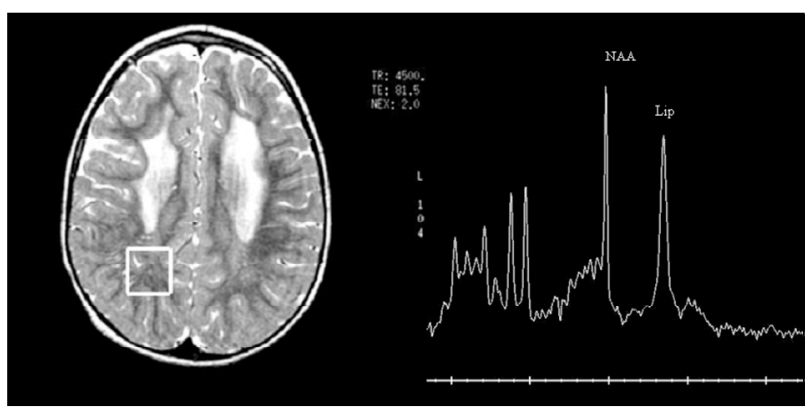

Fig 3. Patient 3- Single voxel ${ }^{1} \mathrm{H}$-MRS (TE=35 ms). The voxel is located at the periventricular white matter and shows a high and sharp lipid peak. Axial T2-weighted FSE (Fast Spin Echo) image shows hyperintensity in the periventricular white mat ter and corona radiata.

n o rmal signal intensity at the peritrigonal white matter on T2-weighted images with normal signal intensity on T1weighted images (Figs $2 \mathrm{~A}$ and $2 \mathrm{~B}$ ). ${ }^{1} \mathrm{H}-\mathrm{MRS}$ (single and multivoxel, TE=35 ms and $144 \mathrm{~ms}$ ) demonstrated a significantly high and sharp lipid peak and a low NAA peak (Fig 2C).

Case 3 - A 4-year-old boy was born after an uneventful full term pregnancy and normal delivery. The pare $n t s$ a re $3^{\text {rd }}$ degree cousins. Developmental delay was noted since very early infancy. He began sitting after his fourth anniversary with assistance and could speak only a few words.

Examination revealed spastic tetraplegia, mental retardation, scoliotic deformity and ichthyosis on trunk and limbs. His weight was $15 \mathrm{~kg}$ (percentile 25) and his height $100 \mathrm{~cm}$ (percentile 25). Neurological examination demon- 
strated increased deep tendon reflexes and clonus. Nerve conduction studies were normal.

Brain MRI study showed periventricular white matter high signal on T2-weighted images and increased lipid peak on ${ }^{1} \mathrm{H}$-MRS (single and multivoxel, TE=35 ms and $144 \mathrm{~ms}$ ) (Fig 3). The area of abnormally high signal intensity on T2weighted images had a decreased signal intensity on T1weighted images.

$\mathrm{MRI}$ and ${ }^{1} \mathrm{H}-\mathrm{MRS}$ of the brain were obtained in a single session for each patient using the same 1.5 T MR unit (Signa Horizon LX Echo Speed; GE Medical System, Milwaukee, WI, USA), and a standard head coil. Imaging was carried out with axial ( $5 \mathrm{~mm}$ and $3 \mathrm{~mm})$, sagittal $(5 \mathrm{~mm}$ ) and coronal $(5 \mathrm{~mm})$ slices, with the following sequences: spin-echo (SE) T1-weighted: echo time (TE), $10 \mathrm{~ms}$; repetition time (TR), 500 msec; and fast spin-echo (FSE) T2-weighted: (TE/TR) 100/2000 msec.

The conventional T2-weighted MR images were used to position a spectroscopic volume of interest (VOI), for single and multivoxel spectroscopy, in areas of abnormal signal in the periventricular white matter. Spectroscopy volume selection was performed by using a PROBE-P sequence (Proton Brain Examination) a version of the PRESS sequence (Point-resolved Proton Spectroscopy Sequence) (TR=2000, $\mathrm{TE}=35 \mathrm{~ms}$ or $\mathrm{TE}=144 \mathrm{~ms}$ ). Each voxel measured $20 \mathrm{~mm} \times 20$ $\mathrm{mm} \times 20 \mathrm{~mm}$. MR spectroscopy data were accumulated after the optimal water signal was suppressed by the chemical shift-selective technique. Institutional review board approval was obtained. A verbal consent was obtained from all parents.

\section{DISCUSSION}

SLS is a rare autosomal recessive disorder with a clinical triad of ichthyosis, mental retardation and spastic diplegia or tetraplegia. It was first described in 1957, with an incidence of 1:200000 births ${ }^{8}$.

SLS is due to deficient activity of fatty aldehyde dehy d rogenase. This enzyme catalyses the oxidation of long chain aldehyde to fatty acids ${ }^{2,3}$. Due to deficiency of this enzyme, there is an accumulation of aldehyde-modified lipids or fatty alcohol in the skin and in the myelin. FALDH plays an essential role in leucotriene B (LTB4) metabolism and a defective degradation of LTB4 may be responsible for considerable pruritus in patients with SLS. FALDH gene has been mapped to the SLS locus on band 17p11.2,2.

Ichthyosis is a generalized hyperkeratosis of the t runk, joints and the dorsal aspects of the hands and the feet. Most patients have erythema at birth, with worsening of cutaneous symptoms during the first year of life. Pruritus is a prominent feature that is not found in other types of ichthyotic skin disorders, and has been recognized as an important symptom that strongly suggests the diagnosis of SLS ${ }^{8}$.

Neurological features are nonspecific; however, mental retardation and developmental delay are usually obvious at 1-2 years of age. Spasticity may be apparent before age 3 years and is more severe in the lower limbs ${ }^{1,2}$.

Photophobia, macular dystrophy and decreased visual acuity are the most prominent ophthalmologic abnormalities, and may be caused by accumulation of long-chain fatty alcohols or fatty aldehydes ${ }^{2}$.

There is a paucity of case reports on SLS imaging findings. Gomori et al. ${ }^{5}$ studied six siblings by $\mathrm{CT}$ and found low confluent density areas in the cerebral white matter, and stated that the severity of the CT findings correlated with the severity of the neurological symptoms. Altinok et al. ${ }^{6}$ reported MRI findings of three siblings with diagnosis of SLS confirmed by enzyme analysis. Brain MRI showed diffuse white matter abnormalities mostly in retrotrigonal and periventricular areas, with no contrast enhancement.

Ve ry limited data are available about ${ }^{1} \mathrm{H}$-MRS in this condition. ${ }^{1} \mathrm{H}-\mathrm{MRS}$ directed to periventricular lesions revealed an abnormally high peak at the lipid range and decreased peak of NAA. A decreased NAA is an indicator of neuronal and axonal damage or dysfunction. It has been re p o rted that the increased relative concentration of lipids correspond precisely to the high signal areas observed on T2-weighted $\mathrm{MRI}^{1,2,7,10}$.

Van Domburg et al. ${ }^{1}$ evaluated 11 SLS patients, and serial MRI findings showed evidence of delayed myelination and a variable degree of dysmyelination in young patients, particularly at the subcortical association areas of the frontal, parietal and temporal lobes. At the early infancy stage there were no MRI evidence of demyelination or dysmyelination. Six patients underwent ${ }^{1} \mathrm{H}-\mathrm{MRS}$ investigation directed to the white matter which showed an abnormal lipid peak, both at a TE=30 and $135 \mathrm{~ms}$. The most intense lipid peaks were localized on periventricular and peritrigonal areas.

Willemsen et al. ${ }^{2}$ re p o rted a clinical, biochemical and molecular characteristics of 19 patients with SLS who presented periventricular white matter abnormalities on MRI and abnormal lipid peak on ${ }^{1} \mathrm{H}-\mathrm{MRS}$ studies. Miyanomae et al. ${ }^{7}$ described a SLS case whose MRI showed high signal on T2-weighted and low signal on T1-weighted images at the peritrigonal areas. ${ }^{1} \mathrm{H}$-MRS of those lesions revealed increased lipid peak. They speculated that such lipids in the periventricular regions with high T2 signal might be pathognomonic of SLS.

Although abnormal lipid peak on ${ }^{1} \mathrm{H}$-MRS have 
been observed in other degenerative diseases, including peroxisomal disorders and multiple sclerosis, the spectral peaks were usually broad and disappeare $d$ on long TE sequences ${ }^{11,12}$.

In a recent paper, Willemsen et al. reported that abnormalities on MRI and proton spectroscopy during the first years of life and that the lipid peak at $1.3 \mathrm{ppm}$ in the proton MRI spectrumof the cerebral white matter may offer a quantitative parameter for monitoring the effects of therapeutic interventions ${ }^{13}$.

The MRI and ${ }^{1} \mathrm{H}$-MRS findings of the three SLS patients studied by us correlate well with those described by the reviewed literature, showing periventricular white matter changes on MRI and a significantly high and sharp lipid peak on ${ }^{1} \mathrm{H}-\mathrm{MRS}$. In a series of 18 patients, Willemsen et al. found normal levels of NAA at ${ }^{1} \mathrm{H}-\mathrm{MRS}$, by comparison with healthy subjects ${ }^{11}$. In our cases, we found slightly decreased NAA $\mathrm{Cr}$ ratio. However, it must be stressed that we did not compare these results with a control group.

${ }^{1} \mathrm{H}$-MRS findings of the patient 2 revealed a high lipid peak, although only minimal signal abnormality was found in the periventricular white matter. We speculate that ${ }^{1} \mathrm{H}-\mathrm{MRS}$ may demonstrate an accumulation of free lipids in the white matter even before an abnormality become detectable by morphological MRI.

The diagnosis of SLS should be considered in any neonate or infant with a congenital ichthyosis associated to neurological features. Biochemical confirmation can be obtained by demonstration of enzyme deficiency of FALDH measured in cultured skin fibrob- lasts or leukocytes, or by the presence of abnormal metabolites of LTB4 in the urine.

We conclude that ${ }^{1} \mathrm{H}$-MRS may be a useful tool for confirmation of SLS diagnosis, suggesting local accumulation of unusual free lipids or lipophilic substances at periventricular white matter.

\section{REFERENCES}

1. Van Domburg PHMF, Willemsen MAAP, Rotteveel JJ, et al. SjögrenLarsson syndrome: clinical and MRI/MRS findings in FALDH-deficient patients. Neurology 1999;52:1345-1352.

2. Willemsen MAAP, Ijlst L, Steijlen PM, et al. Clinical, biochemical and molecular genetic characteristics of 19 patients with the Sjögren-Larsson syndrome. Brain 2001;124:1426-1437

3. Rizzo WB, Craft DA. Sjögren-Larsson syndrome: deficient activity of the fatty aldehyde dehydrogenase component of fatty alcohol: NAD+ oxireductase in cultured fibroblasts. J Clin Invest 1991;88:1643-1648.

4. Hussain MZ, Aihara M, Oba H, et al. MRI of white matter changes in the Sjögren-Larsson syndrome. Neuroradiology 1995;37:576-577.

5. Gomori JM, Leibovici V, Zlotogorski A, Wi rguin I, Haham-Zadeh S. Computed tomography in Sjögren-Larsson syndrome. Neuroradiology 1987;29:557-559.

6. Altinok D, Yildiz YT, Seçkin G, Altinok G, Tacal T, Eryilmaz M. MRI of th re siblings with Sjögren-Larsson syndrome. Pediatr Radiol 1999; 29:766-769.

7. Miyanomae $\mathrm{Y}$, Ochi M, Yoshioka H, et al. Cerebral MRI and spectroscopy in Sjögren-Larsson syndrome: case report. Neuroradiology 1995;37:225-228.

8. Tercedor J, Garcia A. Síndromes neurocutáneos queratósicos. Rev Neurol 1997;25 (Supl 3):S238-S242.

9. Pigg M, Jagell S, Sillen A, Weissenbach J, Gustavson KH, Wadelius C. The Sjögren-Larsson syndrome gene is close to D17S805 as determined by linkage analysis and allelic association. Nat Genet 1994;8:361-364.

10. Mano T, Ono J, Kaminaga T, et al. Proton MR spectroscopy of SjögrenLarsson syndrome. AJNR 1999;20:1671-1673.

11. Wolinsky JS, Narayana PA, Fenstermacher MJ. Proton magnetic resonance spectroscopy in multiple sclerosis. Neurology 1990;40:1764-1769.

12. B ruhn H, Kruse B, Korenke GC, Hanefeld F, Hanicke W, Merboldt KD. P roton NMR spectroscopy of cerebral alterations in infantile peroxisomal disorders. J Comput Assist Tomogr 1992;16:335-344.

13. Willemsen MAAP, van der Graaf M, van der Knaap MS, et al. MR imaging and proton MR spectroscopic studies in Sjögren-Larsson syndrome: characterization of the leukoencephalopathy. AJNR 2004;25:649-657. 